\title{
DAYSIDE RED AURORAS AT VERY HIGH LATITUDES: THE IMPORTANCE OF THERMAL EXCITATION
}

\author{
Vincent B. Wickwar ${ }^{1}$ and Wlodek Kofman ${ }^{2}$ \\ ${ }^{1}$ Radio Physics Laboratory, SRI International \\ ${ }^{2}$ Centre d'Études des Phénomènes Aléatoires et Géophysiques, St. Martin D'Hères, France
}

\begin{abstract}
Extensive radar observations have been made from Sondrestrom of the $F$ region in the daytime sector between 70 and $79^{\circ} \Lambda$. Regions of enhanced electron temperature and electron density are found in close association with the velocity reversal in the morning and afternoon convection cells. From the radar measurements, calculations are made of the contributions to the atomic oxygen emission at $6300 \mathrm{~A}$ from dissociative recombination and thermal excitation. The latter mechanism, in particular, in the enhancement regions gives rise to intensities that are comparable to those observed at very high latitudes during the past decade.
\end{abstract}

\section{Introduction}

For more than a decade [see review by Shepherd, 1979] optical observations at very high latitudes $\left(73\right.$ to $\left.78^{\circ} \Lambda\right)$ on the dayside of the earth have identified regions of intense ( 1 to $4 \mathrm{kR}$ ) $6300-\mathrm{A}$ emission. Although on the dayside, these observations have been in the winter hemisphere at such locations that the sun was well below the horizon. The high intensity regions, which are limited in latitude ( 1 to $\left.5^{\circ}\right)$ and extended in longitude ( 1 to $10 \mathrm{hrs}$ ), have been associated with either magnetospheric features, the cusp and cleft [Shepherd, 1979, and references therein], or ionospheric features, the morning and afternoon convection cells [Reiff et al., 1978]. The source of excitation for the atomic oxygen has been attributed to low energy electrons [Shepherd, 1979, and references therein]. Possible mechanisms for the excitation have been examined by combining theoretical models and observations [Gault et al., 1981; Link et al., 1983], with the conclusion that direct electron impact and dissociative recombination dominate.

The radar observations at Sondrestrom provide a new set of ionospheric and atmospheric parameters [Wickwar et al., 1984] to use to learn about this emission. The results of this initial study show excitation by thermal electrons to dominate much of the time and confirm, to a great extent, the work of Reiff et al. [1978].

We have examined 14 sets of radar observations between April and September 1983, which were obtained in the general survey mode [Wickwar et al., 1984]. From these we have selected 23 April 1983 to examine (Kp values of 4-, 4-, $3,2,2,2+, 2$, and 5). Much information on the data acquisition and analysis is given by Wickwar et al. [1984] and references therein, but derivation of the 6300 - $\mathrm{A}$ emission

Copyright 1984 by the American Geophysical Union.

Paper number 4L6186.

0094-8276/84/004L-6186\$03.00 rates for dissociative recombination and thermal impact are given in the next section. Because Sondrestrom is sunlit at noon throughout the year, correlative optical measurements are very difficult to make. We anticipate having such comparisons in the future.

\section{Technique}

Radar data can be used to calculate the 6300-A emission rate profile and intensity arising from dissociative recombination and impact excitation by thermal electrons. The former procedure has been described by Wickwar et al. [1974] and Cogger et al. [1979] and has been applied to quiet conditions at high latitude [Wickwar, 1974]. The rate constants have been updated to those used by Link et al. [1981] along with the excitation of $1.10\left({ }^{1} \mathrm{D}\right)$ per $0_{2}^{+}$recombination. Instead of determining the $0^{+}$density from the electron density Ne with a chemical equilibrium calculation, a fixed altitude-dependent ratio of $0^{+}$to $\mathrm{Ne}$, which is used for all the data processing, is applied.

The second procedure is based on the rate at which energy is lost from thermal electrons in exciting the $0\left({ }^{l} D\right)$ state [Stubbe and Varnum, 1972], the loss of $1.95 \mathrm{eV}$ per photon excited, and the emission probability. It is a function of the electron temperature $\mathrm{Te}$, neutral temperature $\mathrm{Tn}, \mathrm{Ne}$, and neutral density. $\mathrm{Ne}$ and $\mathrm{Te}$ are available from the radar measurements. The neutral parameters are from the Jacchia [1971] model atmosphere with the exospheric temperature $T_{\infty}$ determined from the radar measurements [Kofman and Wickwar, 1984]. During the portion of 23 April 1983 discussed below, $\mathrm{T}_{\infty}$ is $1300 \mathrm{~K}$ prior to $1600 \mathrm{UT}, 1250 \mathrm{~K}$ afterwards.

\section{Observations and Calculations}

In Figures 1-3 we examine in detail an early afternoon elevation scan, between 1623 and 1628 UT (subtract $3 \mathrm{hrs}$ for local standard time and approximately $2 \mathrm{hrs}$ for magnetic local time). In Figure 4 we give an overview of the daytime sector between 70 and $79^{\circ} \Lambda$.

Figures 1(a)-1(f) show, respectively, $\mathrm{Ne}, \mathrm{Te}$, ion temperature Ti, energy loss rate Le from thermal electrons to ions and neutrals, 6300-A volume emission rate e(6300) from dissociative recombination, and $\mathrm{e}(6300)$ from thermal excitation. An Ne enhancement 1 to $2^{\circ}$ in width occurs near $77^{\circ}$ $\Lambda$ in the $F$ region, but does not appear to extend down into the $\mathrm{E}$ region. It could arise from precipitation or transport. But, the coincident increase in $\mathrm{Te}$, to above $4000 \mathrm{~K}$ at 450 $\mathrm{km}$, strongly suggests particle precipitation. This conclusion is reinforced by the coincident increase in Le, which is a better indicator of energy input than Te. The e(6300) from 


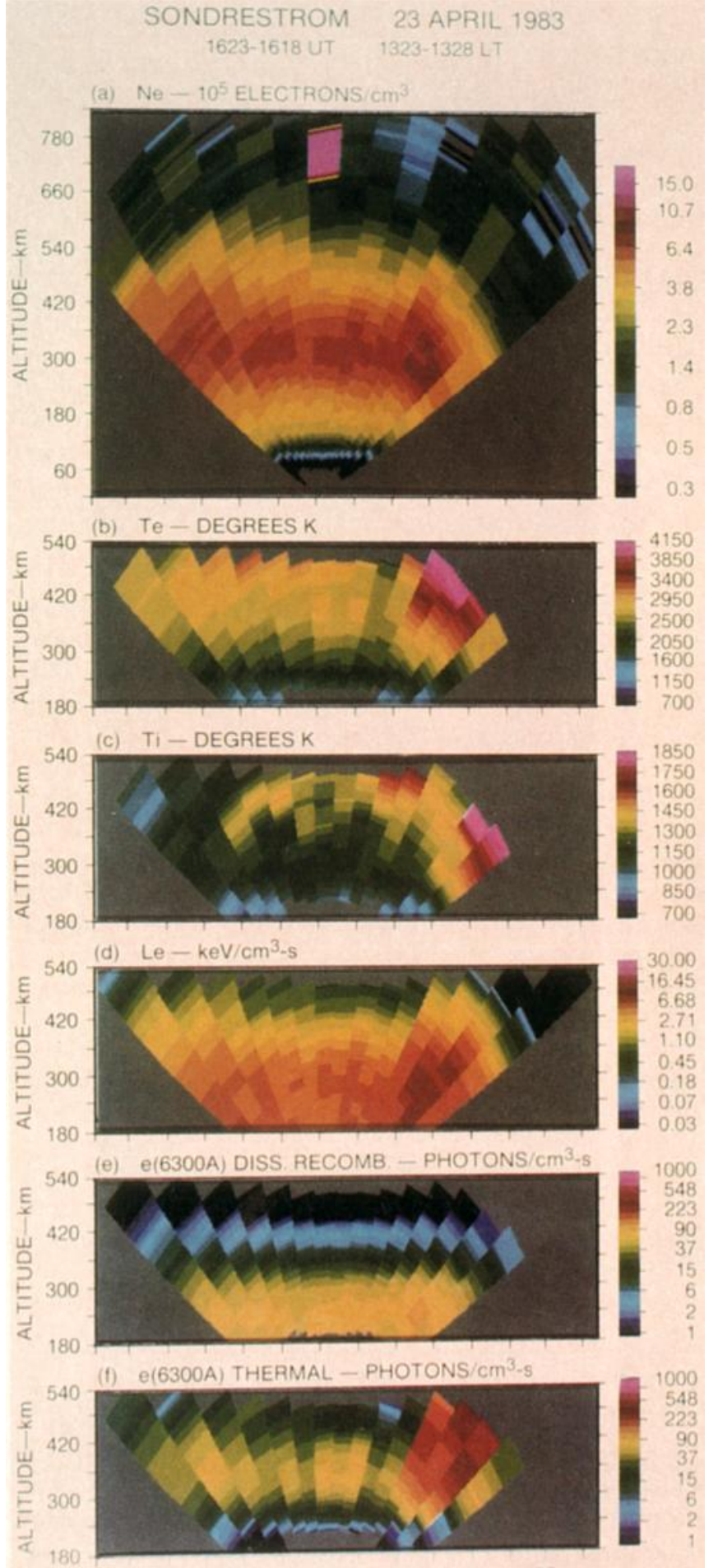

Fig 1. Elevation scan for 1623 to 1628 UT on 23 April 1983: (a) $\mathrm{Ne}$, (b) $\mathrm{Te}$, (c) $\mathrm{Ti}$, (d) Le, (e) e(6300) for dissociative recombination, (f) e(6300) for thermal excitation. (The magneto region at $74^{\circ} \Lambda$ and $720 \mathrm{~km}$ is a satellite.)

dissociative recombination has a peak altitude just below $250 \mathrm{~km}$ and maximum value near $77^{\circ} \Lambda, 100$ photons $/ \mathrm{cm}^{3}$-s compared with a background of 60 . The e(6300) from thermal excitation has a peak altitude just above $350 \mathrm{~km}$ at most latitudes and $400 \mathrm{~km}$ near $77^{\circ} \Lambda$ The maxımum value is 300

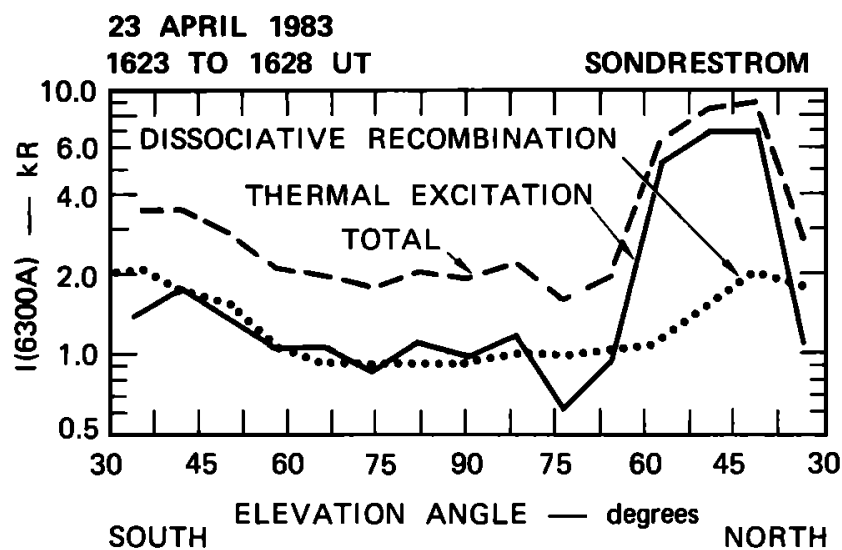

Fig. 2. Line-of-sight $\mathrm{I}(6300 \mathrm{~A})$ for 1623 to $1628 \mathrm{UT}$ on 23 April 1983.

photons $/ \mathrm{cm}^{3}$-s compared with a background of 50

When we integrate the emission rates along the line of sight and convert to Rayleighs we obtain contributions to the intensity I $(6300 \mathrm{~A})$ that a meridian-scanning photometer with an $8^{\circ}$ field of view would detect (Figure 2). Each mechanism contributes about $1 \mathrm{kR}$ overhead. The most prominent structures are the expected van Rhijn effect at low elevation angles and a big $7 \mathrm{kR}$ thermal increase between 40 and $55^{\circ}$ elevation angle in the north [The increase would go to higher elevation angles if e(6300) were calculated to higher altitudes.]

Figure 3 shows VEAST and VNORTH, obtained by averaging together multiposition velocity determinations before and after the elevation scan. The gap corresponds to the radar location, under the westward (sunward) convection in the evening cell. The enhancements are located at the sharp reversal from westward to eastward convection at $77^{\circ}$ $\Lambda$. The regions of large ion velocities, 74.5 to 76.5 and, in particular, poleward of $78^{\circ} \Lambda$, presumably give rise to the elevated ion temperatures in Figure 1(c), which straddle instead of coinciding with the other enhancements

Figure 4(a)-4(d) shows $\mathrm{Ne}, \mathrm{Te}, \mathrm{Ti}$, and Le, respectıvely at 350-km altitude. The e(6300) are integrated as in Figure 2 and assigned altitudes near the emission peaks, i.e., $250 \mathrm{~km}$ for dissociative recombination and $350 \mathrm{~km}$ for thermal impact. These intensities are shown in Figures 4(e) and (f), respectively. Superimposed on each part of the figure are

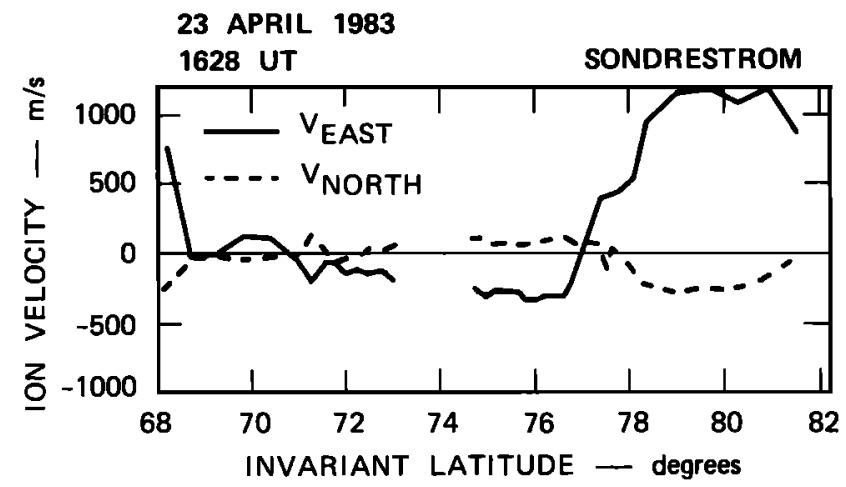

Fig. 3. Ion velocity components for 1628 UT On 23 April 1983. 


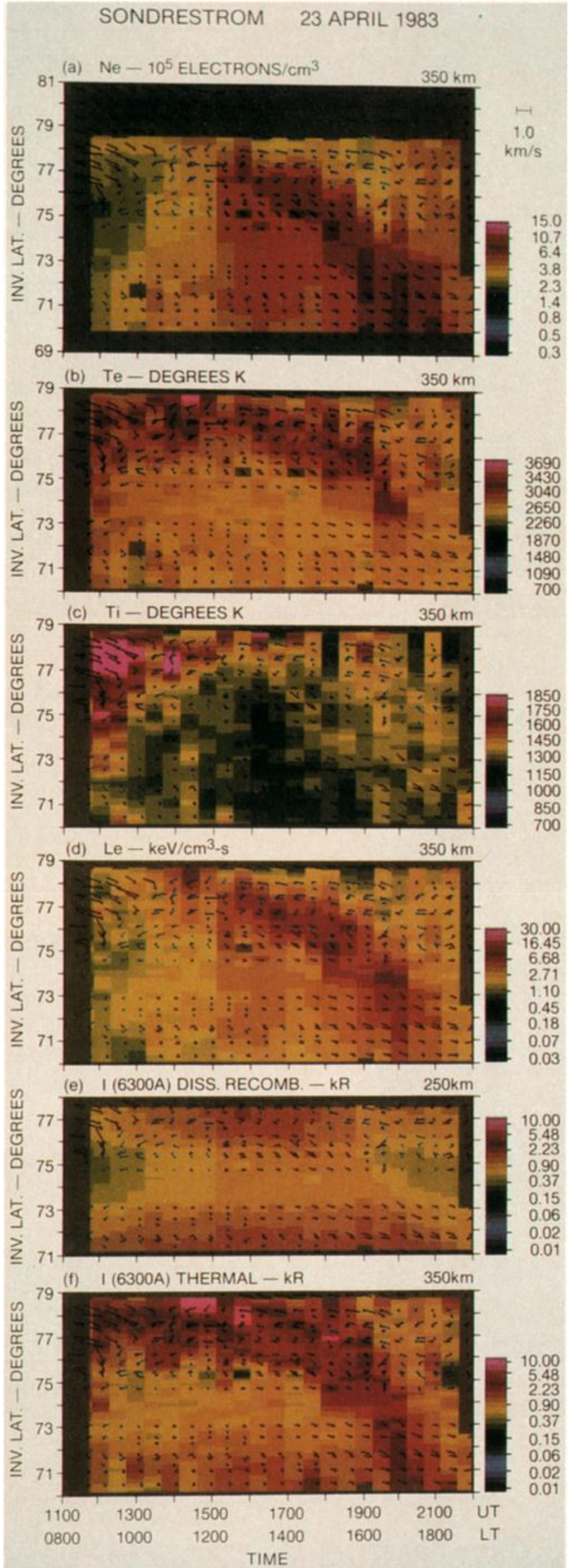

arrows showing the ion convection pattern. The radar is in three different positions with respect to it: from 1100 to $1400 \mathrm{UT}$ it is under the morning cell, from 1400 to $1500 \mathrm{UT}$ it is between the two cells, and from 1500 to 2200 UT it is under the evening cell.

In the morning, elevation scans show two energy input regions, one equatorward and one poleward of the reversal In the latter $\mathrm{Ne}$ and Le have their maxima at higher altitudes suggesting lower energy particle precipitation. Despite high convection velocities leading to considerable Joule heating and an $\mathrm{Ne}$ reduction in much of this period, $\mathrm{Ne}$ and $\mathrm{Te}$ remain high poleward of the convection reversal and give rise to strong predicted $\mathrm{I}(6300 \mathrm{~A})$.

Between 1400 and 1500 UT the situation is not as clear Increases in $\mathrm{Ne}$ and $\mathrm{Te}$ occur near the northern limits of observation and the predicted $\mathrm{I}(6300 \mathrm{~A})$ increase. The vector velocities are hard to interpret. They appear unorganized, which probably indicates that the actual velocities change significantly over scales that are small compared to the separation of measured points [Wickwar et al., 1984]. In contrast, the line-of-sight velocities in the magnetic mer1dian clearly show a poleward component of the velocity of about $500 \mathrm{~m} / \mathrm{s}$ in the northern part of the field of vew This northern region is possibly what is identified as the low altitude extension of the cusp.

After 1500 UT and prior to $1830 \mathrm{UT}$, a sharp convection reversal exists in the evening cell and the data are well ordered with respect to it. $\mathrm{Ne}$ is elevated at and just equatorward of it. Te is elevated at and poleward of it Le and I(6300A) from thermal excitation are largest at the reversal Their increases are biggest when the east-west convection reversal is sharpest. After 1830 UT the reversal is less sharp and the maximum westward velocity is considerably equatorward of the reversal. The region of maximum Le and thermal I(6300A) also shift equatorward.

\section{Discussions and Conclusion}

In close association with the convection reversal in the morning and afternoon cells and between the cells at noon there is substantial energy input. Because of F-region increases in $\mathrm{Ne}$, as well as $\mathrm{Te}$, at least part of the energy input is from low energy electrons, although Kofman and Wickwar [1984] have shown considerable downward heat flux under some conditions. A consequence of the $\mathrm{Ne}$ and $\mathrm{Te}$ enhancements is that the calculated $\mathrm{I}(6300 \mathrm{~A})$ from thermal impact (with a contribution from dissociative recombination) is great enough to more than account for reported very high latitude observations. Our results are in qualıtatıve agreement with the theoretical work of Roble and Rees [1977] for the "nighttime cusp." For the "daytime cusp" they did not find thermal excitation as important, because their Te were too small. But Te could increase and thermal excita-

Fig. 4. Spatial distribution of parameters for 23 April 1983: (a) $\mathrm{Ne}$ at $350 \mathrm{~km}$, (b) Te at $350 \mathrm{~km}$, (c) Ti at $350 \mathrm{~km}$, (d) Le at $350 \mathrm{~km}$, (e) $\mathrm{I}(6300 \mathrm{~A})$ from dissociative recombination plotted at $250 \mathrm{~km}$, (f) I $(6300 \mathrm{~A})$ from thermal excitation plotted at $350 \mathrm{~km}$. Vector ion velocities are superimposed on the other parameters Vectors with an eastward component are in blue; those with a westward component are in red 
tion could become important if there were a significant downward heat flux. In contrast, our results do not agree with previous combinations of observations and theory [Gault et al., 1981; Link et al., 1983] which dismiss the importance of thermal excitation. While we do not have correlative 6300-A intensities, they did not have correlative electron temperatures. We expect to have both next year. If both avenues of research turn out to be correct, then the apparent contradiction would have to arise from a physical difference such as greater energy input into F-region electrons in summer and near equinox than in mid winter. We expect to look for seasonal variation in the radar data in the near future.

As stated, the location of the energy input and predicted $\mathrm{I}(6300 \mathrm{~A})$ in the morning and afternoon is closely associated with the convection cells as predicted by Reiff et al. [1978]. This association with the convection cells, where local particle acceleration occurs, contributes to the question of whether the cleft $I(6300 \mathrm{~A})$ arises from magnetosheath particles or not.

Acknowledgments. We thank the many SRI personnel who have helped make this research possible. In particular, we appreciate the considerable efforts of Carol Leger and Sam Todd. The Sondrestrom radar is operated by SRI International under NSF cooperative agreement ATM8121671. This research has been supported in part by the above, by AFOSR contract F49620-83-K-0005, and by CNRS.

\section{References}

Cogger, L. L., J. C. G. Walker, J. W. Meriwether, Jr., and R. G. Burnside, F-region airglow: are ground-based observations consistent with recent satellite results? $J$. Geophys. Res., 85, 3013-3020, 1979.

Gault, W. A., R. A. Koehler, R. Link, and G. G. Shepherd, Observations of the optical spectrum of the dayside magnetospheric cleft aurora, Planet. Space Sci., 29, 321-333, 1981.

Jacchia, L. G., Revised static models of the thermosphere and exosphere with empirical temperature profiles, Smithson. Astrophys. Obs. Rep., 332, 1971.
Kofman, W., and V. B. Wickwar, Very high electron temperatures in the daytime $\mathbf{F}$ region at Sondrestrom, Geophys. Res. Lett., this issue, 1984.

Link, R., J. C. McConnell, and G. G. Shepherd, A selfconsistent evaluation of the rate constants for the production of the 0I 6300A airglow, Planet. Space Sci., 29, 589-594, 1981.

Link, R., J. C. McConnell, and G. G. Shepherd, An analysis of the spatial distribution of dayside cleft optical emissions, J. Geophys. Res., 88, 10,145-10,162, 1983.

Reiff, P. H., J. L. Burch, and R. A. Heelis, Dayside auroral arcs and convection, Geophys. Res. Lett., 5, 391-394, 1978.

Roble, R. G., and M. H. Rees, Time-dependent studies of the aurora: effects of particle precipitation on the dynamic morphology of ionospheric and atmospheric properties, Planet. Space Sci., 25, 991-1010, 1977.

Shepherd, G. G., Dayside cleft aurora and its ionospheric effects, Rev. Geophys. and Space Phys., 17, 2017-2033, 1979.

Stubbe, P., and W. S. Varnum, Electron energy transfer rates in the ionosphere, Planet. Space Sci., 20, 1121-1126, 1972.

Wickwar, V. B., Conjugate photoelectrons at $\mathrm{L}=5.6$ and the 6300 A post-sunset enhancement, Planet. Space Sci., 22, 1297-1307, 1974.

Wickwar, V. B., L. L. Cogger, and H. C. Carlson, The $6300 \mathrm{~A} 0\left({ }^{1} \mathrm{D}\right)$ airglow and dissociative recombination, Planet. Space Sci., 22, 709-724, 1974.

Wickwar, V. B., J. D. Kelly, O. de la Beaujardière, C. A. Leger, F. Steenstrup, and C. H. Dawson, Sondrestrom Overview, Geophys. Res. Lett., this issue, 1984.

V. B. Wickwar, Radio Physics Laboratory, SRI International, 333 Ravenswood Avenue, Menlo Park, CA 94025.

W. Kofman, CEPHAG (LA346), B. P. 46, 38402 St. Martin d'Hères, France

(Received May 15, 1984; revised July 24, 1984; accepted July 25, 1984.) 